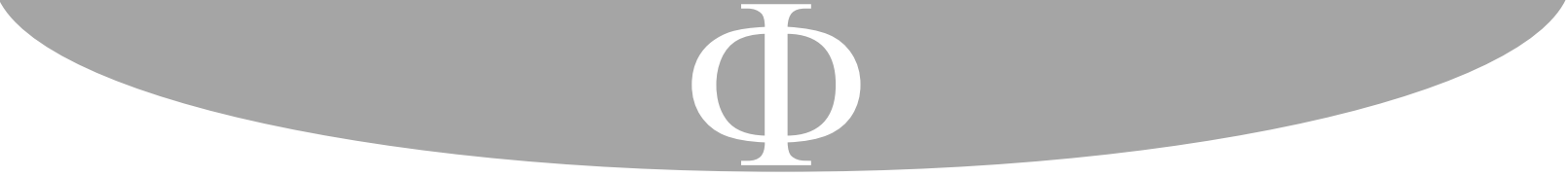

\title{
La banalización del morir. Una aproximación a las políticas de la memoria histórica desde la perspectiva de Paul Ricœur y Hannah Arendt
}

\author{
Begoña Rúa Zarauza* \\ Instituto Superior de Ciencias Religiosas «San Melchor de Quirós» \\ - Universidad Pontificia de Salamanca. \\ Oviedo, España
}

Para citar este artículo: Rúa Zarauza, Begoña. «La banalización del morir. Una aproximación a las políticas de la memoria histórica desde la perspectiva de Paul Ricœur y Hannah Arendt».

Franciscanum 177, Vol. 64 (2022): 1-14.

\section{Resumen}

La cuestión que se plantea es la relación que puede haber entre la crisis de legitimación de las sociedades contemporáneas, tras el declive de los grandes sistemas teóricos y metafísicos previos a la Ilustración, y la actual proliferación de las políticas de la memoria histórica. Apoyándose en los autores contemporáneos Paul Ricœur y Hannah Arendt, en este trabajo subyace la idea de que dichas políticas tratan de subsanar la ausencia de legitimación y, tal vez, de esperanza. Cabe preguntarse, en fin, si los cuerpos políticos están poniendo el acento en el verdadero bien supremo, que no es otro que la vida.

\section{Palabras clave}

Memoria histórica, muerte, política, Paul Ricœur, Hannah Arendt.

\section{The banality of dying. An approach to the politics of historical memory from the perspective of Paul Ricœur and Hannah Arendt.}

\begin{abstract}
The question that is posed is the relationship that may exist between the crisis of legitimation in contemporary societies, after the decline of the great theoretical and metaphysical systems pre-Enlightenment, and the current proliferation of the politics of historical memory. Relying on the contemporary authors Paul Ricœur and Hannah Arendt, this work underlies the idea that these policies try to correct the lack of legitimation and, perhaps, of hope. Finally, it is worth asking if the political bodies are outlining the true supreme good which is none other than life.

\footnotetext{
* Licenciada en Filosofía en la Universidad de Barcelona. Doctora en Filosofía por la Universidad de Barcelona (UB) y la Escuela de Estudios Superiores en Ciencias Sociales (EHESS) de París. Profesora de Historia de la Filosofía. Instituto Superior de Ciencias Religiosas, «San Melchor de Quirós» (afiliado a la Universidad Pontificia de Salamanca). Oviedo, España. ORCID: 0000-0001-5336-9168. Contacto: begona.rua@aulasemiovi.com.
} 


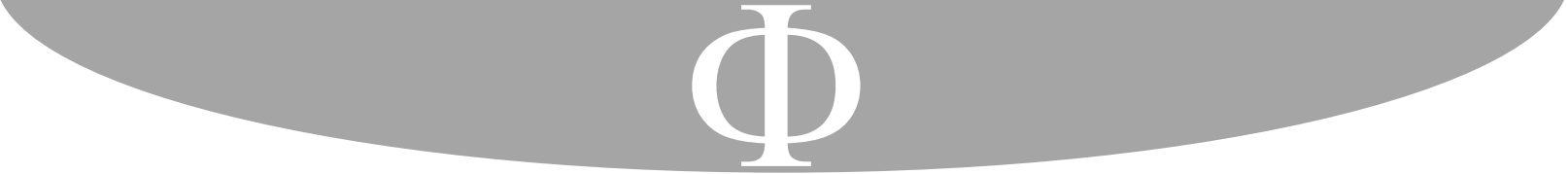

Keywords

Collective memory, death, politics, Paul Ricœur, Hannah Arendt.

\section{Planteamiento de la cuestión}

Tal como el autor francés Paul Ricœur señala en la parte dedicada a la ética en su obra Sí mismo como otro ${ }^{1}$, la vida en sociedad se organiza en torno a instituciones, reglas, leyes, principios, intereses, etc. Aspectos todos ellos que se fundan en los grandes sistemas teóricos, metafísicos y religiosos de la humanidad ${ }^{2}$. Grandes sistemas que, a nuestro modo de entender, están orientados al futuro con una visión, en el caso de la religión, escatológica, contribuyendo a generar y a sostener los principios, valores y proyectos ideológicos de las sociedades. Ahora bien, con el declive de los grandes sistemas de pensamiento que sucede a la Ilustración, las sociedades actuales pasan por una crisis de legitimación y de orientación que, entre otras cosas, podría explicar, el creciente interés en las políticas de memoria histórica. En otros términos, la crisis de legitimación que afecta a las sociedades contemporáneas podría explicar la proliferación de políticas de la memoria que, en muchos casos, imponen de forma abusiva y manipuladora ya sea el recuerdo, a través de un sinnúmero de conmemoraciones, ya sea el olvido, a través del derribo y eliminación de los monumentos y otras pervivencias históricas. La cuestión de la memoria histórica está a la base de la investigación y el estudio de Ricœur en su obra La Memoria, la historia, el olvido ${ }^{3}$ cuyo objeto es, conforme a su equilibrado talante filosófico e intelectual, la búsqueda de una política de la justa memoria ${ }^{4}$. A este respecto, Ricœur plantea la cuestión desde el perdón en lo que éste contribuye a la constitución de la memoria histórica y al necesario olvido en el sentido determinado que el perdón le confiere.

\section{La crisis de legitimación y las políticas de la memoria histórica}

Dos de los términos del título de la obra de Ricœur, la memoria y la historia, reenvían a la crisis de legitimación y a la proliferación de las políticas de la memoria planteadas en el párrafo precedente. Si consideramos, en primer término, la cuestión de la memoria, en el tratado Sobre la memoria y la reminiscencia ${ }^{5}$, Aristóteles afirma que «la memoria es sobre el pasado» ${ }^{6}$ y otro tanto podría decirse respecto a la historia. No obstante, la cuestión del pasado reenvía al problema ontológico del estatuto que cabe conceder a una especie de «ser»

\footnotetext{
${ }^{1}$ Paul Ricœur, Sí mismo como otro, (París: Seuil, 1990), 304.

2 Paul Ricœur, Sí mismo como otro, 304.

${ }^{3}$ Paul Ricœur, Sí mismo como otro, 24.

${ }^{4}$ Paul Ricœur, La mémoire, l'histoire et l'oubli (Paris: Seuil, 2000), 24. En el prólogo el autor señala: «je reste troublé par l'inquiétant spectacle que donnent le trop de mémoire ici, le trop d'oubli ailleurs, pour ne rien dire de l'influence des commémorations et des abus de mémoire - et d'oubli. L'idée d'une politique de la juste mémoire est à cet égard un de mes thèmes civiques avoués».

${ }^{5}$ El tratado se halla en «Parva naturalia». Breves tratados de la Historia Natural (Barcelona: Planeta-De Agostini, 1996).

${ }^{6}$ Aristóteles, «Parva naturalia» 449 b 15.
} 


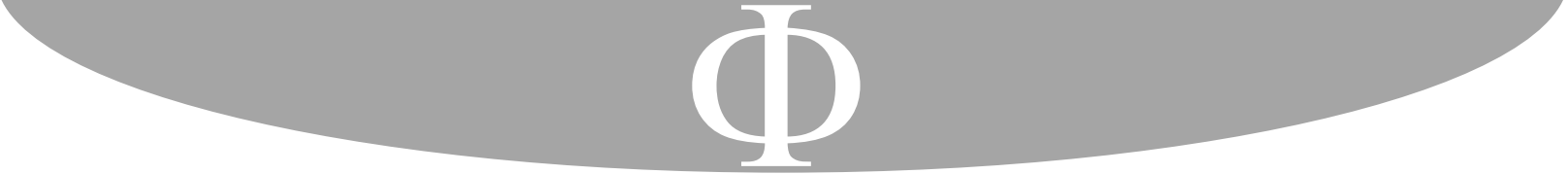

ausente, a algo que ha sido pero que ya «no es» ${ }^{7}$ y a lo que no es posible acceder de otro modo que a través de la imaginación o, en su caso, del documento o registro que testifique de su existencia pasada. Entran en juego, además, la historia y la transmisión generacional de la tradición y la cultura que contribuyen a vehicular y a mantener la memoria del pasado. La memoria se mantiene y se trasmite a través de la historia y las obras de la cultura, particularmente de la cultura escrita y, a partir de finales del siglo XIX, mediante el registro de grabaciones sonoras y visuales o bien, de manera más general, con la ayuda de las aportaciones que ofrecen las nuevas tecnologías.

Respecto a las obras de la cultura, ya sean las obras de arte como la pintura o la escultura, el cine, la música, la literatura, etc., queda clara una cierta idealización o bien la aportación subjetiva y original de los autores. No obstante, dicha aportación original supone una visión del mundo y de la realidad difícilmente desprovista de un enfoque moral. Las obras de la cultura son capaces de expresar y dar forma a los grandes ideales, valores o sentimientos como el amor, el odio, la cólera, la envidia de la humanidad. «¿Qué sabríamos nosotros — plantea Ricœur - del amor y del odio, de los sentimientos éticos (...) si no hubiesen sido expresados a través del lenguaje y articulados por la literatura?» ${ }^{8}$. Por otro lado, en términos del mismo autor, las cuestiones de ética reenvían a una ética concreta (Sittlichkeit): la ética reconocida y expresada en la fenomenología hegeliana, y contenida en las costumbres, leyes y tradiciones de los pueblos y comunidades a través de tiempos inmemoriales ${ }^{9}$. En resumen, los grandes ideales y valores éticos de la humanidad se trasmiten mediante la cultura y ésta responde a un enfoque ideológico y moral determinado.

Otro tanto puede afirmarse de la historia considerada como texto escrito, esto es, la historiografía. La consideración de la disciplina histórica a partir de la escritura, teniendo en cuenta el hecho de que se trata de un texto escrito y, en este sentido, comparable a otros textos escritos como puede ser la literatura o la ficción, aparece en el dominio de la filosofía crítica de la historia hacia los años setenta del siglo pasado. La historiografía es la rama de la historia que considera la escritura o estructura narrativa de la historia como un elemento constitutivo de la representación del pasado. De este modo, la referencia de la historia como disciplina ya no serán únicamente las ciencias positivas sino la literatura en general, y particularmente las obras en prosa ${ }^{10}$. La consideración de la historia como historiografía tiene en cuenta la ambigüedad de la historia que es, de manera simultánea, relato y acontecimiento. No obstante, el mostrar la peculiaridad de la historia como realidad que conlleva los aspectos subjetivo y objetivo al mismo tiempo, se debe al gran genio de Hegel ${ }^{11}$. La comprensión

\footnotetext{
${ }^{7}$ Paul Ricœur, La mémoire, l'histoire et l'oubli.

${ }^{8}$ Paul Ricœur, «La fonction herméneutique de la distanciation», en Du texte à l'action (Paris: Seuil, 1998$), 130$.

${ }^{9}$ Paul Ricœur, «La fonction herméneutique de la distanciation», 279.

10 Paul Ricœur, «Philosophies critiques de l'histoire: Recherche, explication, écriture», en Philosophical problems Today. Vol I, editado por G. Fløistad (Dordrecht-Boston-London: Kluwer Academic Publishers, 1994).

${ }^{11}$ Reinhart Koselleck, histora/Historia (Madrid: Trotta, 2010), 45: «Cuando Hegel establecía que "La historia reúne en nuestra lengua (alemana) tanto el lado subjetivo como el objetivo y significa tanto la historia rerum gestarum como la res gestas misma", no apreciaba esto como algo que no fuera una "contingencia exterior".
} 


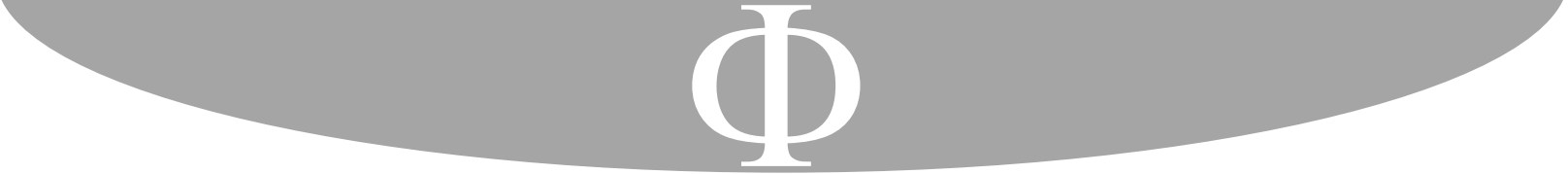

dialéctica de las realidades humanas como siendo al mismo tiempo subjetivas y objetivas significa que son obras humanas, por tanto, subjetivas, y objetos materiales, en consecuencia, objetivas. El propio Ricœur parte de esta comprensión de la historia en su obra Tiempo y narración donde sostiene que en todo relato o narración histórica hay algo de ficticio, en la medida en que se trata de una elección y de una disposición de los hechos o acontecimientos de un modo determinado, y en toda narración ficticia hay algo de real, al menos en el sentido de lo posible, de aquello que es capaz de transformar la realidad ${ }^{12}$. De este modo, la distinción entre ciencia y ficción no es radical: la ficción es el medio de expresar los valores, aspiraciones y sentimientos humanos más profundos e inasequibles al discurso directo, y las realidades científicas, en la medida en que son obras humanas, suponen un componente subjetivo ineludible.

La consideración de la historia como forma literaria ha sido desarrollada por intelectuales anglosajones y franceses. Hyden White en su obra Metahistory: The Historical Imagination in XIX ${ }^{\text {th }}$ Century Europe ${ }^{13}$, muestra la estructura de las obras de historia: la crónica hace posible el orden temporal a través de la sucesión, la trama o story introduce un comienzo, un medio y un fin en el orden puramente secuencial y desarrolla la intriga, que sitúa el relato en una clase de relatos, sea la novela, la tragedia, la comedia o la sátira. Del mismo modo, siguiendo la teoría de la ideología elaborada por Karl Mannheim, Hyden distingue cuatro estrategias de implicación ideológica mediante las cuales los historiadores pueden sugerir a los lectores la importancia de sus estudios del pasado para la comprensión del presente: anarquismo, radicalismo, conservadurismo y liberalismo ${ }^{14}$. En el ámbito francés, la crítica de la historia como escritura forma parte de la estrategia general de sospecha y de las manifestaciones anti-humanistas de la tradición althusseriana, según la cual, las distintas formas de representación histórica y literaria responden a estructuras ideológicas que contribuyen a la formación de individuos adaptados al sistema.

\footnotetext{
Los "hechos y eventos propiamente históricos", que dejaban tras de sí el espacio, previo a lo histórico, de los sucesos naturales, sólo se había originado, a la vez que su elaboración, en el medio de la narración de historias. Lo uno remite a lo otro, y a la inversa.»

${ }^{12}$ Paul Ricœur, Temps et récit III. Le temps raconté (Paris: Seuil, 1991), 330. En el capítulo «L'entrecroisement de l'histoire et la fiction» el autor señala: «Par entrecroisement de l'histoire et de la fiction, nous entendons la structure fondamentale, tant ontologique qu'épistémologique, en vertu de laquelle l'histoire et la fiction ne concrétisent chacune leur intentionnalité respective qu'en empruntant leur intentionnalité à l'autre.»»

${ }^{13}$ Hyden White, Metahistory: The Historical Imagination in XIXth Century Europe, trad. Stella Mastrangelo 1973. Metahistoria. La imaginación histórica en la Europa del s. XIX (México: Fondo de Cultura Económica, 1992).

${ }^{14}$ Hyden White, Metahistoria. La imaginación histórica en la Europa del s. XIX, 405. «Siguiendo la teoría de las ficciones de Northrop Frye, he identificado cuatro arquetipos diferentes de estructuras de trama por medio de los cuales los historiadores pueden figurar procesos históricos en sus narraciones como relatos de un tipo particular: novela, tragedia, comedia y sátira. Y empleando la teoría de la ideología elaborada por Karl Mannheim, he discernido cuatro estrategias diferentes de implicación ideológica por medio de las cuales los historiadores pueden sugerir a sus lectores la importancia de sus estudios del pasado para la comprensión del presente: anarquismo, radicalismo, conservadurismo y liberalismo».
} 


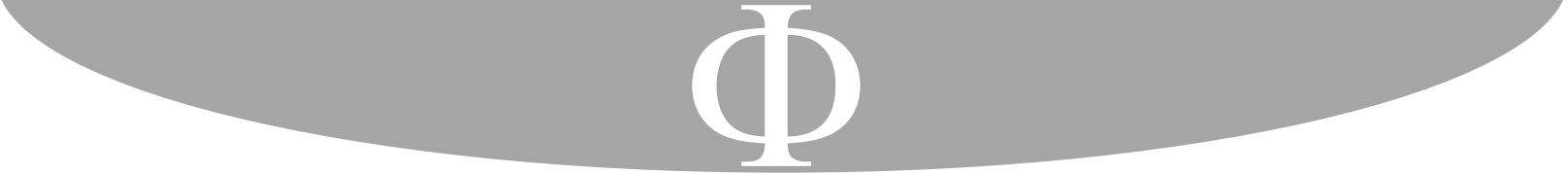

Memoria e historia se ajustan o cumplen una función ideológica que contribuye a perpetuar los sistemas de poder. De hecho, el sistema de poder que gobierne en un momento o lugar concreto impone el aprendizaje y la celebración de una determinada memoria oficial. No se trata, sin embargo, de negar el valor de la memoria y la historia, ni su necesidad, ni el beneficio que conlleva la restauración de la justicia. En los términos de la escritora Isak Dinesen, a quién Hannah Arendt cita en La condición humana: «Todas las penas pueden soportarse si las ponemos en una historia o contamos una historia» ${ }^{15}$. Conforme a la teoría de la propia Arendt, memoria e historia contribuyen a configurar la identidad de las personas y de los pueblos. No se trata pues, de poner en cuestión la función restauradora y sanadora de las conmemoraciones y duelos en recuerdo de las víctimas del pasado, ni se pretende restar importancia a la memoria del pasado y la tradición. Particularmente las religiones dan testimonio del valor de mantener el recuerdo del pasado mediante la trascendencia y respeto que otorgan a las tradiciones y a su historia fundadora. La cuestión que nos ocupa, no obstante, son los abusos de la memoria histórica, tal como Ricœur señala en La memoria, la historia y el olvido, y la crisis de legitimación que podría estar a la base de su motivación.

\section{Memoria, Historia y Mortalidad}

En La condición humana, Arendt desarrolla el concepto de acción, la praxis reivindicada por las teorías políticas de la modernidad, particularmente por el marxismo. La noción de acción es pertinente respecto a las políticas de la memoria histórica en la medida en que, en términos de la autora: «se compromete en establecer y preservar los cuerpos políticos, [creando] la condición para el recuerdo, esto es, para la historia» ${ }^{16}$. Lo más relevante, a nuestro modo de entender, es la forma en que la autora vincula la noción de acción al pensamiento y a la vida. En el primer caso, el vínculo de la acción al pensamiento es conforme a la tradición filosófica y, representa una forma de reivindicación de dicha tradición. En el segundo caso, el vínculo de la acción con la vida es conforme a la tradición cristiana y, como en el caso de la reivindicación de la tradición filosófica, constituye una defensa.

Arendt sostiene que la expresión vita activa está cargada de tradición ${ }^{17}$. La autora sitúa el surgimiento de la noción en el juicio de Sócrates, símbolo del conflicto entre el filósofo, el libre pensador, y la polis, el sistema de poder vigente. En la antigüedad clásica y conforme a la democracia ateniense, la vita activa correspondería a la forma de vida que podían elegir los hombres libres, y la verdadera forma de ejercer la libertad plena, teniendo en cuenta el juicio al que Sócrates fue sometido. En otros términos, el juicio de Sócrates ejemplifica la plena libertad de pensamiento del individuo frente a las presiones y condicionamientos del cuerpo político. El pensamiento es posible cuando el ser humano vive en libertad política, de hecho, sería la capacidad más susceptible de ceder a la violencia ${ }^{18}$, si

\footnotetext{
${ }^{15}$ Hannah Arendt, La condición humana (Barcelona: Paidós, 2005), 199.

${ }^{16}$ Hannah Arendt, La condición humana, 22.

${ }^{17}$ Hannah Arendt, La condición humana, 25.

${ }^{18}$ Hannah Arendt, La condición humana, 348.
} 


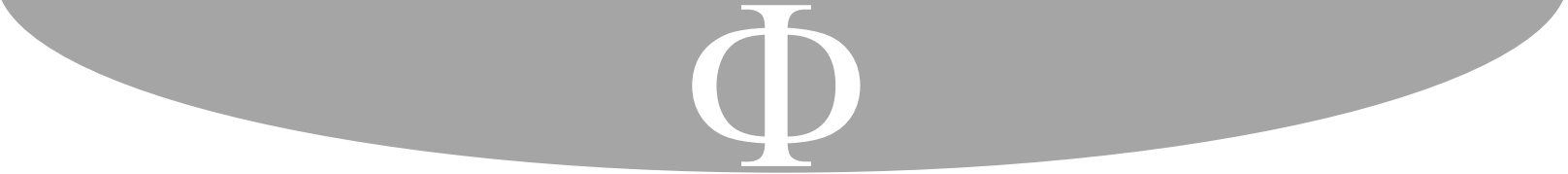

bien, el juicio de Sócrates demuestra lo contrario. Por otro lado, el requisito de la libertad supone la posibilidad de dedicarse a la actividad más elevada del ser humano: pensar. La vida dedicada al pensar, al conocimiento, requería la liberación de los quehaceres cotidianos, sean las labores impuestas por las necesidades biológicas, sean los trabajos de los artesanos y comerciantes para recibir su sustento. La vida activa así concebida, a través de la plena libertad de las necesidades y exigencias del sustento, se aplicaría también al ciudadano de la polis que podía entregarse en cuerpo y alma a los asuntos políticos. No obstante, Arendt defiende que esta noción de acción tendió a desaparecer con la caída de la antigua ciudadestado y terminó perdiendo significado político para denotar cualquier clase de compromiso activo con el mundo. La acción pasaría entonces a considerarse como una actividad más entre las necesidades de la vida ordinaria, y la contemplación (la vida teórica), pasaría a representar lo que antiguamente significaba la vita activa manteniéndose como la única forma de vida que permite dedicarse enteramente a las tareas propias del pensar.

Según Arendt, pensamiento y acción habrían comenzado a separarse en la tradición ética y política surgida en la escuela de Sócrates. Los filósofos habrían comprendido que no era la vita activa de la política, sino la vita theorica (contemplativa) de la filosofía, la que ponía en juego las acciones más elevadas del ser humano, aquellas que son involucradas en el pensar. Para explicar este proceso la autora recurre a la contraposición entre la idea de inmortalidad, que sería propia a la vía que puede ofrecer la vía política, y la eternidad, que es la vía contemplativa. La inmortalidad correspondería a la permanencia específica de la vida sin muerte del mundo y la naturaleza en su ciclo continuo e ininterrumpido. Arendt sostiene que en la antigüedad griega se consideraba que, en el ciclo de la naturaleza, tan solo los seres humanos son mortales, pues incluso los animales existen como miembros de la especie y su vida inmortal estaría garantizada por la procreación. Sin embargo, el ser humano es mortal a causa de su individualidad, por su cualidad de ser único cuya vida discurre entre los dos límites del nacimiento y la muerte. La única forma de inmortalidad a la que el ser humano podía aspirar sería la que otorga el talento de producir cosas duraderas o el coraje de realizar grandes hazañas, perpetuando la memoria a través de las generaciones.

Por su capacidad para realizar actos inmortales, por su habilidad en dejar huellas imborrables, los hombres, a pesar de su mortalidad individual, alcanzan su propia inmortalidad y demuestran ser de naturaleza «divina». La distinción entre el hombre y el animal se observa en la propia especie humana: sólo los mejores (aristoi), quienes constantemente demuestran ser los mejores (...) y «prefieren la fama inmortal a las cosas mortales», son verdaderamente humanos; los demás, satisfechos con los placeres que les proporciona la naturaleza, viven y mueren como animales ${ }^{19}$.

Pero la fama inmortal, o el recuerdo que permanece en la memoria, no es eterna. Hannah Arendt expresa la contradicción inherente entre la vida del filósofo y su preocupación por lo eterno, y la vida del ciudadano que aspira a la inmortalidad del recuerdo. La autora reconoce esta contradicción en el mito de la caverna donde la contemplación de lo eterno

${ }^{19}$ Hannah Arendt, La condición humana, 31. 


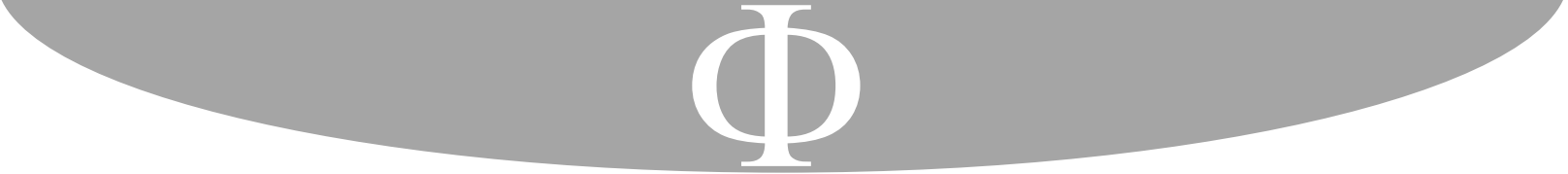

sólo se da tras la liberación del ser humano de las trabas que le atan a los demás y del abandono de la caverna en completa soledad. La autora señala que esta experiencia, descubierta por el filósofo, se denominaría teoría o contemplación para distinguirla de las demás actitudes que, como máximo, atañen a la inmortalidad mundana. No obstante, la victoria de la preocupación por la eternidad sobre las aspiraciones hacia la inmortalidad mundana, no se debe al pensamiento filosófico sino al auge del cristianismo que acompaña a la caída del Imperio Romano ${ }^{20}$. El final del Imperio habría mostrado que ninguna obra humana es inmortal y el crecimiento del evangelio cristiano, que predica una vida individual imperecedera, pasó a ocupar un lugar exclusivo en la religiosidad de Occidente.

Esta aspiración a la inmortalidad, de la que Arendt se apropia para distinguirla de lo eterno, aparece magistralmente expresada en el diálogo sobre el amor del Banquete ${ }^{21}$. La cuestión surge en el momento en el que la profetisa Diotimia ilustra a Sócrates sobre el amor:

Si quieres reparar en el amor de los hombres por los honores, te quedarías asombrado también de su irracionalidad, a menos que medites en relación con lo que yo he dicho, considerando en qué terrible estado se encuentran por el amor de llegar a ser famosos «y dejar para siempre una fama inmortal». Por esto, aún más que por sus hijos, están dispuestos a arrostrar todos los peligros, a gastar su dinero, a soportar cualquier tipo de fatiga y a dar su vida. Pues ¿crees tú — dijo- que Alcestis hubiera muerto por Admeto o que Aquiles hubiera seguido en su muerte a Patroclo o que vuestro Codro se hubiera adelantado a morir por el reinado de sus hijos, si no hubiera creído que iba a quedar de ellos el recuerdo inmortal que ahora tenemos por su virtud? Ni mucho menos - dijo-, sino que más bien, creo que por inmortal virtud y por tal ilustre renombre hacen todo, y cuanto mejores sean, tanto más, pues aman lo que es inmortal ${ }^{22}$.

En los tiempos modernos y contemporáneos Arendt reivindica un concepto de acción desvinculado del activismo político, y la plena actualidad de la filosofía en el sentido clásico, para acceder a la verdad. La vita activa, la acción, tal como Arendt la entiende y reivindica, es el acto mismo del pensar: la reflexión, el diálogo entre "yo y yo mismo», el diálogo interior en el que uno habla consigo mismo. Diálogo de uno consigo mismo en el que, señala la autora, Sócrates y Platón ${ }^{23}$ veían la esencia del pensamiento ${ }^{24}$. Sin embargo, la cualidad de este diálogo es justamente lo opuesto a la comprensión ordinaria y política de la acción desde el momento en el que supone el cese, más o menos completo, de las demás actividades ${ }^{25}$. La autora entiende la acción al modo clásico de los griegos y latinos, tal como se expresa en el célebre adagio: "Numquan se plus agere quam nihil cum agent, numquam minus esse quam cum solus esset» («Nunca se está más activo que cuando no se hace nada, nunca se está menos solo que cuando se está consigo mismo»). Del mismo modo, Arendt reivindica la

\footnotetext{
${ }^{20}$ Hannah Arendt, La condición humana, 33.

${ }^{21}$ Platón, Diálogos III, Banquete, trad. C. García Gual, M. Martínez Hernández y E. Lledó Íñigo (Madrid: Gredos, 1998), 208, c-e.

${ }^{22}$ Platón, Diálogos III. Fedón, Banquete, Fedro, 208, c-e.

${ }^{23}$ Platón, Diálogos, Gorgias (Madrid: Gredos, 1987), 482 a-e.

${ }^{24}$ Hannah Arendt, La condición humana, 81 y 317.

${ }^{25}$ Hannah Arendt, La condición humana, 317.
} 


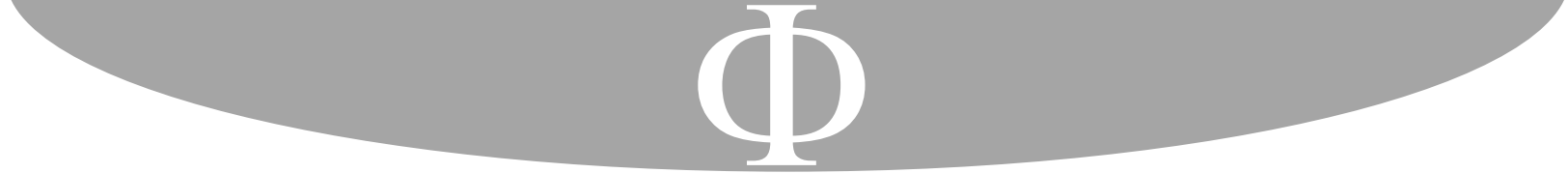

capacidad de la reflexión, de la filosofía, para acceder al conocimiento y la verdad. Conocimiento y acceso a la verdad que, tras el auge de las ciencias experimentales y positivas, ha quedado prácticamente supeditado a dichas ciencias.

Como pensadora política, la autora reconoce la necesidad de un ámbito público y la transformación del mundo en una comunidad de cosas capaz de relacionar a las personas entre $s^{26}$. Dicho espacio exige la permanencia a través del tiempo, la durabilidad que trascienda a las generaciones de los vivos y la mortalidad de las personas. Sin embargo, nada es comparable al bien supremo de la vida, y este aspecto, la autora lo reconoce y lo enfatiza, se debe al cristianismo.

La razón de que la vida se afirmara como fundamental punto de referencia en la Época Moderna y de que siga siendo el supremo bien de la sociedad moderna, radica en que la inversión moderna se operó en la estructura de una sociedad cristiana cuya creencia principal en la sacralidad de la vida ha sobrevivido —e incluso ha permanecido inamovible - a la secularización y a la general decadencia de la fe cristiana ${ }^{27}$.

La sacralidad y la esperanza que la novedad cristiana confirió a la vida humana son únicas. El nuevo mensaje no prometía la mortalidad mundana, ni el recuerdo resistente al paso del tiempo. La «buena nueva» cristiana prometía la inmortalidad del individuo, la vida eterna de la persona individual, comparada a la cual la permanencia en la memoria y la historia se convertía en mera ilusión, en vanagloria. De este modo, y contrariamente a la acusación de alienación que critican Feuerbach y el marxismo, la inmortalidad que la revelación cristiana prometía a la persona aumentó el valor de la vida terrena. Del mismo modo, el vínculo de la acción al nacimiento, resaltado por la autora como la posibilidad de un nuevo comienzo, probablemente se inspire en el valor inalienable y supremo que el cristianismo concede a la vida pues, en sus propios términos:

Cabe que la vida terrena no sea más que la primera y más miserable etapa de la vida eterna, a pesar de todo es vida, y sin esta vida que termina con la muerte, no puede haber vida eterna. Tal vez sea esta la razón del indiscutible hecho de que sólo cuando la inmortalidad de la vida individual se convirtió en el credo central de la humanidad occidental, es decir, sólo con el auge del cristianismo, la vida terrena pasó a ser el bien supremo del hombre ${ }^{28}$.

En la era contemporánea la pervivencia de estos principios está más que amenazada. Lo que ofrecen las corrientes materialistas y fisicalistas del pensamiento es el hecho bruto de la naturaleza y una promesa de bienestar que ninguna sociedad es capaz de colmar. La vida humana ha recuperado la mortalidad de la antigüedad clásica previa al cristianismo, con el agravante de que el mundo y la vida política actuales son más inestables y, en cierto modo, banales. Tras el vacío inmenso que deja la pérdida de la fe y la esperanza cristianas, el ser

\footnotetext{
${ }^{26}$ Hannah Arendt, La condición humana, 64.

${ }^{27}$ Hannah Arendt, La condición humana, 338.

${ }^{28}$ Hannah Arendt, La condición humana, 340.
} 


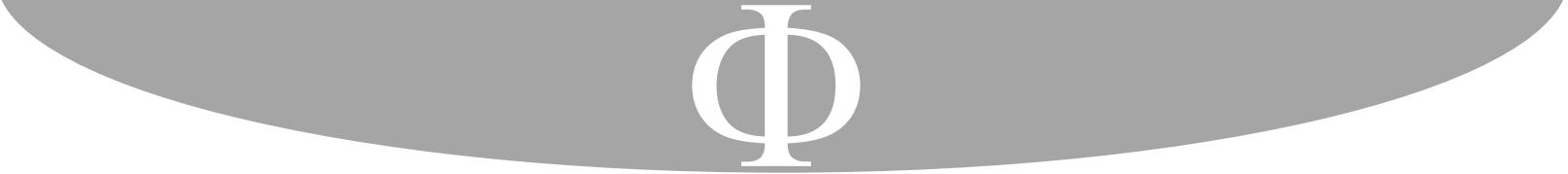

humano tampoco ha sido capaz de recuperar la estabilidad que le ofrecía el mundo antiguo. Volcado sobre sí mismo, consciente de la propia subjetividad y de las astucias de la razón humana para esquivar el hecho de la mortalidad, el ser humano ni siquiera está seguro de saber qué es lo real. Tal es la pérdida de fundamentos y de legitimidad a la que se aludía al principio a propósito de la caída de los grandes sistemas teóricos y metafísicos. El individuo moderno sometido a la duda cartesiana y al descrédito kantiano de la metafísica, tiene certeza de sí mismo, pero ha perdido su alma, el mundo y a Dios. Ya no somos cuerpo y alma, pues lo que llamamos alma es un cerebro; el mundo, la historia, son el resultado de la reconstrucción y manipulación humana de la naturaleza bruta; y Dios es la idea en la que se condensan las aspiraciones totalizantes de la razón y el deseo de eternidad.

\section{La resolución estoica frente a la muerte}

La memoria y la historia versan sobre el pasado, se señalaba al inicio y, sin embargo, la deconstrucción heideggeriana del tiempo en Ser y Tiempo muestra la primacía del futuro. De hecho, es el futuro lo que cuenta para el historiador que pretende dejar una huella de lo acontecido $^{29}$. Siguiendo el legado de Agustín de Hipona, Heidegger analiza la cuestión del tiempo a partir de las tres instancias fundamentales: pasado, presente y futuro. Agustín de Hipona respondía al argumento escéptico que negaba la existencia del tiempo, mediante la idea del triple presente. El argumento escéptico sostiene que el tiempo carece de ser, de existencia, pues el pasado ya no existe, el presente es inaprensible y el futuro no existe aún. La solución del triple presente responde a la cuestión situando las cualidades del pasado, presente y futuro en la mente: «Los tiempos son tres: presente de las cosas pasadas, presente de las cosas presentes y presente de las futuras. Porque estas son tres cosas que existen de algún modo en el alma (...): presente de cosas pasadas (memoria), presente de cosas presentes (visión), presente de las cosas futuras (expectativa) ${ }^{30}$. Paralelamente al triple presente agustiniano, Heidegger desarrolla el análisis del tiempo a partir de tres etapas o aspectos: la temporeidad, que remplazaría al presente agustiniano, la historicidad, noción relativa al pasado, y la intratemporeidad, equivalente al presente del ser-en-el-tiempo. El análisis del tiempo se funda, a su vez, en la comprensión del individuo como Dasein, el «ente que somos en cada caso nosotros mismos y que entre otras cosas, tiene esa peculiaridad de ser que es el preguntar» ${ }^{31}$. El ser que cada uno de nosotros somos en cada caso, tiene la peculiaridad de preguntarse, de cuestionarse, es decir que, entre todas las formas de ser que hay en el mundo, el ser que cada uno somos en cada caso es un ser consciente. Consciencia que se caracteriza por el cuidado (Sorge) del Dasein que se confronta a sí mismo como totalidad, es decir, como ser circunscrito entre los límites del nacimiento y la muerte.

\footnotetext{
${ }^{29}$ Paul Ricœur, La memoria, la historia y el olvido (México: Fondo de Cultura Económica, 2004), 450-451 (p. 453 de la versión original en francés).

${ }^{30}$ Agustín de Hipona. Confesiones, trad. José Cosgaya, O.S.A. (Madrid: Biblioteca de Autores Cristianos, 1997), 26.

${ }^{31}$ Martín Heidegger, Ser y Tiempo, trad. J.E. Rivera (Madrid: Trotta, 2018), 18.
} 


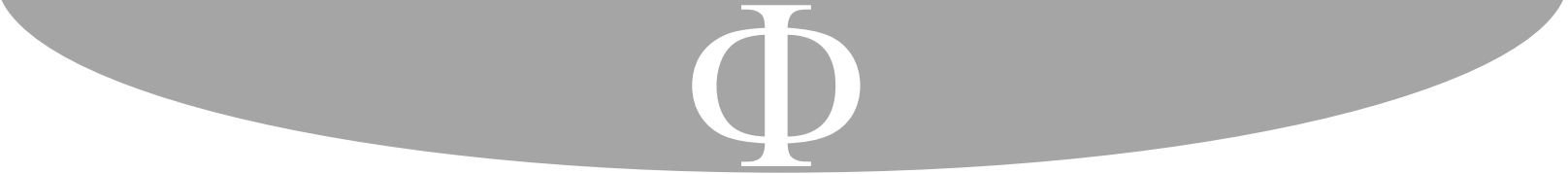

La noción de temporeidad se refiere al tiempo comprendido en su unicidad: el tiempo es un todo cuya característica fundamental, según el análisis existencial de Heidegger, no es el devenir, el sucederse de las cosas pasadas, sino el advenir, la expectación siempre inminente del futuro. Lo que adviene, el futuro, permanece presente por su necesidad ineludible con el agravante de que lo que adviene es siempre la muerte. A partir de esta comprensión fundamental del tiempo, se explicitan las nociones de historicidad e intratemporeidad. La historicidad sustituye de algún modo la noción clásica de historia en la que resalta la memoria del pasado sobre el advenimiento del futuro que caracteriza la noción heideggeriana del tiempo. De este modo, la historicidad es una noción del pasado acorde a la nueva comprensión cuya peculiaridad es la anticipación del futuro. En otros términos, la comprensión del pasado como historicidad indica que éste ya contenía el futuro, es decir, que el pasado contenía el advenimiento del morir siempre presente. En fin, la noción de la intratemporeidad se refiere al presente del cuidado y la preocupación a través de expresiones como «tener tiempo» o «tener tiempo para». Somos un ser en proyecto, hay un proyecto de vida, un querer hacer, lograr, llegar a... y el tiempo del que disponemos para realizar dicho proyecto es limitado e incierto. La única certeza que poseemos es la de su final.

Heidegger denuncia los procesos de abstracción a través de los cuales se establecen los conceptos e ideas universales de la metafísica y de las ciencias en general. En el caso específico del tiempo, mediante el sistema de datación de los calendarios se establecen segmentos o espacios temporales (pasado, presente, futuro, años, meses, días...) en la continuidad del tiempo uno y único. De este modo, las relaciones entre presente, pasado y futuro son universalmente válidas, es decir, aplicables o transferibles a todo tiempo y lugar. El tiempo se comprende entonces como una sucesión indeterminada y vacía de ahoras: una sucesión formal de instantes cuyos intervalos son medidos por los relojes. Gracias a la formalización de este proceso concebimos la realidad temporal como el paso de un instante a otro, de un minuto a otro, de una hora a otra, de un día a otro, de un mes a otro, de un año a otro... Olvidándonos con ello de que se trata siempre de uno y el mismo tiempo, el tiempo del ser humano que vive y habita un entorno y cuya realidad esencial, podría decirse, se caracteriza por la imposibilidad de separar la situación presente del proyecto futuro cuyo límite es la muerte ${ }^{32}$. Heidegger sostiene que el tiempo es finito y solamente finito. Si tenemos el tiempo como algo infinito es debido al proceso de abstracción que lo representa como una sucesión ininterrumpida del ahora que nos orienta hacia una realidad que no tiene principio ni fin. Otro tanto puede aplicarse a la idea de la humanidad: el ser humano no muere, no puede morir porque no tiene existencia real, es únicamente un concepto, una idea general de la realidad que somos todas y cada una de las personas concretas. Heidegger denomina a esta noción el «uno» que somos «todos» y «ninguno» en particular y señala: «El uno no muere jamás, porque no puede morir; en efecto, la muerte es siempre mía ${ }^{33} »$.

\footnotetext{
${ }^{32}$ Además de la citada obra de Heidegger, M., Ser y Tiempo, particularmente la Segunda Sección: Dasein y Temporeidad, los análisis sobre el concepto del tiempo en Heidegger son desarrollados por Paul Ricœur, «La fonction narrative et l'expérience humaine du temps», Archivio di Filosofia 1, Vol. 50 (1980): 343-367. Un desarrollo semejante se halla en la obra del mismo autor: Temps et Récit III.

${ }^{33}$ Martín Heidegger, Ser y Tiempo, § 424-425.
} 


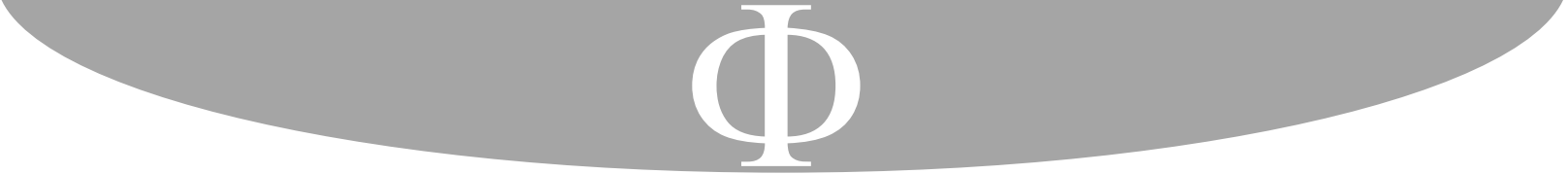

la vida, más allá de cualquier política o ideología y, seguramente, las dramáticas consecuencias de la falta de coherencia moral que muestra el caso de Eichmann resultan lo bastante convincentes.

\section{Consideraciones finales}

Probablemente sea cierto, como se señalaba al principio, que nos hallamos ante una crisis de legitimación y es posible que la proliferación de las políticas de la memoria constituya un dato sintomático. Con el declive de los grandes sistemas ideológicos y metafísicos, las sociedades carecen de la fundamentación y los grandes ideales capaces de movilizar las conciencias, y a la pérdida de la esperanza cristiana le sigue una creciente banalización del morir.

La Ilustración supuso el gran paso de la humanidad hacia la emancipación. En el inolvidable ensayo ¿Qué es la Ilustración? el gran filósofo define la Ilustración como: «el abandono por parte del hombre de una minoría de edad cuyo responsable es él mismo. Esta minoría de edad significa la incapacidad para servirse de su entendimiento sin verse guiado por otro» ${ }^{39}$. De este modo, el lema: Sapere aude! ¡Atrévete a saber por ti mismo!, representa la conquista de la libertad. Una conquista no sólo política o histórica, sino intelectual, que supuso la autoconciencia, el hecho de que la razón se hiciera consciente de sí misma y de su intervención insoslayable en el mundo de los fenómenos. En los términos de Alain Renaut en Kant Aujourd'hui es precisamente en la obra crítica de Kant donde la dimensión subjetiva del entendimiento queda determinada como actividad frente a la simple recepción pasiva de las percepciones sensibles ${ }^{40}$. Brevemente, la novedad aportada por Kant sería el cuestionar la realidad, no a partir de sí misma, sino relativamente al sujeto que se cuestiona sobre dicha realidad.

El auge de la dimensión subjetiva caracteriza la modernidad que se inicia con Descartes y la célebre duda metódica, y su resultado es la primera forma declarada de autoconciencia e introspección subjetiva. Proceso a través el cual, la razón deviene consciente de sí misma al tiempo que pierde certeza sobre el mundo sensible. El «yo pienso», el cogito cartesiano, supuso la ruptura con una comprensión ingenua de la realidad en la que la mente se comportaría como un espejo, fiel reflejo de lo real, o como la cera blanda capaz de recibir pasivamente la forma del sello. La duda metódica puso en cuestión la fiabilidad de los sentidos, pues son engañosos, la incapacidad para distinguir entre los sueños y los estados de lucidez, y la posibilidad de ser manipulado por un genio engañador, un ente superior capaz de burlar a la razón. La mente humana generó así su propio concepto y devino autoconciencia. El camino quedó abierto hasta comprender que la mente no se comporta de forma meramente pasiva frente a los datos proporcionados por los sentidos, sino conforme a

she initiated a series of lectures entitled Some Questions of Moral Philosophy. What follows is the introductory lecture, which, in an edited version, is published here for the first time».

${ }^{39}$ Immanuel Kant, ¿Qué es la Ilustración?, edición de Roberto R. Aramayo (Madrid: Alianza Editorial, 2013).

${ }^{40}$ Alain Renaut, Kant aujourd'hui (Paris: Aubier, 1997). 


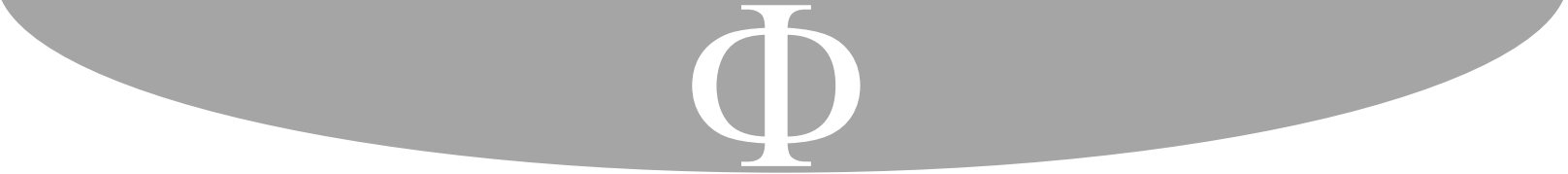

esquemas o estructuras de organización que son previos a toda experiencia. En fin, el grado máximo de la autoconciencia sería expresado, a mi modo de entender, por el genio inigualable de Hegel al mostrar que la intervención humana en el mundo de los fenómenos no es meramente intelectual sino práctica.

A través de la célebre expresión: «Lo real es racional y lo racional es real» que puede traducirse, de manera más propia, como «Lo racional es efectivo y lo efectivo es racional» ${ }^{41}$ quedaba expresada la comprensión de que el mundo humano, la historia, es al mismo tiempo subjetiva y objetiva: obra del ser humano y realidad externa al mismo. Lo real es racional desde el momento en que tiene un sentido, una estructura cognoscible por la razón, y lo racional es real desde el momento en que la razón humana es capaz de crear las realidades humanas a partir de sí misma como si de una segunda naturaleza se tratara. Esta efectividad de la razón, en su dimensión teórica y práctica, resulta magistralmente ilustrada en los Principios de la Filosofía del Derecho donde se lee: «el sistema del derecho es el reino de la libertad realizada, el mundo del espíritu producido a partir de sí mismo como una segunda naturaleza» ${ }^{42}$.

A partir del desarrollo intelectual de la modernidad, ninguna teoría ni forma de pensamiento está exenta de la mediación subjetiva y, por tanto, de la sospecha de ideologización. La modernidad trajo consigo el declive de los grandes sistemas de pensamiento capaces de fundamentar y legitimar el esquema de valores de las sociedades. Con la demolición de los grandes fundamentos, el ser humano conquistó la libertad, pero perdió la esperanza. En este sentido, cabe pensar que la proliferación de la memoria histórica ofrezca un intento de colmar este vacío. Sin embargo, desde nuestro punto de vista, y reafirmando la posición de Arendt, por un lado, el cuerpo político actual no puede ofrecer la estima y la dignidad inspiradas en la inmortalidad mundana de la antigüedad, pues el sistema de valores que lo sustentaba quedó sepultado en el pasado; y, por otro lado, se ha renunciado a la aspiración a la eternidad de la que dan testimonio filósofos y cristianos ${ }^{43}$. A cambio se ofrecen memoriales en recuerdo de las víctimas caídas o la pervivencia en el recuerdo finito de entes finitos.

\section{Bibliografía}

Agustín de Hipona. Confesiones. Traducido por José Cosgaya, O.S.A. Madrid: Biblioteca de Autores Cristianos, 1997.

Arendt, Hannah. The life of the Mind. San Diego, New York, London: A Harvest Book; Harcourt, Inc., 1978.

\footnotetext{
${ }^{41}$ G. W. F. Hegel, Principes de la philosophie du droit, trad. Robert Derathe (Paris: Vrin, 1998), 55; Leçons sur l'histoire de la philosophie, Tome 3, La philosophie grecque. Platon et Aristote, trad. Pierre Garniron (Paris: Vrin, 2007), «Le véritable idéal ne doit pas être effectivement réel, il l'est, lui seul ce qui est effectivement réel (...) et, ce qui est effectivement réel est rationnel».

${ }^{42}$ G. W. F. Hegel, Principes de la philosophie du droit $§ 4,71$ : «Que (le droit) est le règne de la liberté effectuée, le monde de l'esprit produit à partir de l'esprit lui-même, en tant que seconde nature».

${ }^{43}$ Hannah Arendt, La condición humana, 339.
} 


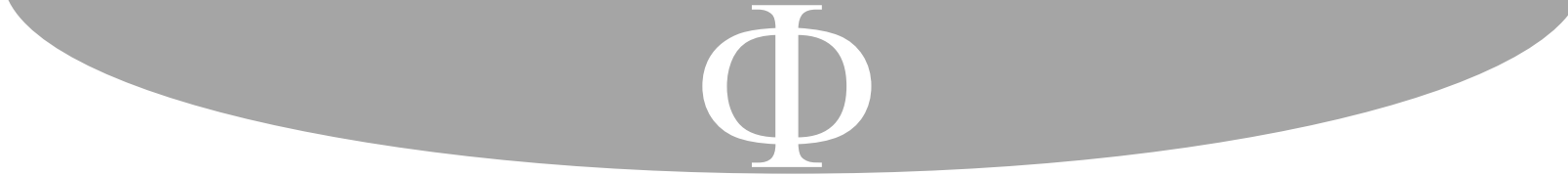

Arendt, Hannah. The Human Condition. Traducido por Gil Novales, R., La condición humana. Barcelona: Paidós, 2005.

Arendt, Hannah. «Some Questions of Moral Philosophy», Social Research 4, Vol. 61 (1994): 739-764.

Aristóteles. Parva naturalia, Breves tratados de la Historia Natural. Barcelona: Planeta-De Agostini, 1996.

Hegel, G. W. F. Principes de la philosophie du droit. Traducido por Robert Derathe. Paris: Vrin, 1998.

Hegel, G. W. F. Leçons sur l'histoire de la philosophie. Tome 3, La philosophie grecque. Platon et Aristote. Traducido por Pierre Garniron. Paris: Vrin, 2007.

Heidegger, Martin. Ser y Tiempo. Traducido por J.E. Rivera. Madrid: Trotta, 2018.

Hyden White. Metahistory: The Historical Imagination in XIX ${ }^{\text {th }}$ Century Europe, 1973. Traducido por Stella Mastrangelo. Metahistoria. La imaginación histórica en la Europa del s. XIX. México: Fondo de Cultura Económica, 1992.

Kant, Immanuel. ¿Qué es la Ilustración? Edición de Roberto R. Aramayo. Madrid: Alianza Editorial, 2013.

Koselleck, Reinhart. Histora/Historia. Madrid: Trotta, 2010.

Platón. Diálogos III. Fedón, Banquete, Fedro. Traducido por C. García Gual, M. Martínez Hernández y E. Lledó Íñigo. Madrid: Gredos, 1998.

Renaut, Alain. Kant aujourd'hui. Paris: Aubier, 1997.

Ricœur, Paul. «La fonction narrative et l'expérience humaine du temps». Archivio di Filosofia 1, Vol. 50 (1980): 343-367.

Ricœur, Paul. Soi-même comme un autre. Paris: Seuil, 1990. Sí mismo como otro. Madrid: Siglo XXI, 1990.

Ricœur, Paul. Temps et récit III. Le temps raconté. Paris: Seuil, 1991.

Ricœur, Paul. «La fonction herméneutique de la distanciation». En Du texte à l'action, Paris: Seuil, 1998.

Ricœur, Paul. «Philosophies critiques de l'histoire: Recherche, explication, écriture». En Philosophical problems Today. Vol I. Editado por G. Fløistad. Dordrecht-BostonLondon: Kluwer Academic Publishers, 1994.

Ricœur, Paul. La mémoire, l'histoire et l'oubli. Paris: Seuil, 2000. Traducido por Agustín Neira. La memoria, la historia, el olvido. México: Fondo de Cultura Económica, 2004.

Enviado: 23 de diciembre de 2020 Aceptado: 7 de febrero de 2021 